\title{
The Crisis of Modern Sport and the Dimension of Achievement for its Conquest
}

\author{
Masami Sekine* and Takayuki Hata** \\ *Faculty of Education, Okayama University \\ 3-1-1 Tsushimanaka, Okayama 700-8530, Japan \\ spsekine@cc.okayama-u.ac.jp \\ ${ }^{* *}$ Faculty of Education, Nagasaki University \\ 1-14 Bunkyômachi, Nagasaki 852-8521, Japan \\ hata@net.nagasaki-u.ac.jp
}

[Received January 28, 2004 ; Accepted September 1, 2004]

\begin{abstract}
The necessity of recognising an ideological basis for overcoming the crisis of modern sport symbolised by doping is set out in this paper. The first part provides the consideration of the influences which doping brings to sport. The second section examines a means for conquering the crisis of sport. The third and final section considers the dimension of achievement, which is different from excellence, and proposes the ideological basis for conquering the crisis of modern sport based on the development of a new sports culture, different from modern sport in its quality, is proposed.
\end{abstract}

Keywords: modern sport, achievement, doping, quality of sport

[International Journal of Sport and Health Science Vol.2, 180-186, 2004]

\section{Introduction}

The greatest danger to modern sport is the use of performance enhancing drugs. "The use of some alleged performance enhancing drugs and practices in sports raises a number of surprisingly complex ethical problems" (Morgan, 2003, p.182). The term "doping" is applied to a specific phenomenon in sport. It refers to the illegal use of drugs in sport for the purpose of increasing performance. The prohibition of doping was a result not only of its undesirable influences on the outcome of sports event but also and more importantly because of its threat to the athlete's health potentially leading to acute harm and fatalities. The subject concerning harm, coercion and fairness has been discussed (Fraleigh, 1985; Schneider \& Butcher, 2000; Tamburrini, 2000). Not only does doping attack ethics and fair play in sports, it puts at risk the health of athletes who will do anything to get a competitive edge. It also threatens the credibility and future of sport in the eyes of parents and children who may look down on a win-at-all-costs attitude.
Anti-doping programs seek to preserve what is intrinsically valuable about sport. The intrinsic value is often referred to as the spirit of sport how we play honestly. The spirit of sport is the celebration of the human spirit, body and mind. It is characterised by the following values: ethics, fair play and honesty; health; excellence in performance; character and education; fun and joy; teamwork; dedication and commitment; respect for rules and laws; respect for oneself and other participants; courage; and community and solidarity. Doping is, therefore, fundamentally contrary to the spirit of sport.

The pursuit of sporting excellence can be represented by the motto "Citius, Altius, Fortius" (International Olympic Committee, 2003, p.19). This motto highlights the principles that uphold the true spirit of sport. Excellence in performance and wholesomeness are two major principles of modern sport. It is becoming more difficult to adhere such qualities because of doping. Schneider and Butcher (2000) says the following: 
While excellence in sport is worthily pursued, it should not be pursued at the expense of one's later health and well being. Because amateur sport is publicly funded, the community is in a position to put limits on its support; limits that come from the desire to promote human excellence across a complete lifetime. (p.198)

How will the general population judge sport and its participants if doping continues progressively? Athletes will no longer be supported and sport will lose its appeal and social value.

In this paper, on such recognition, the necessity of an ideological basis for overcoming the crisis of modern sport symbolised by doping will become apparent.

\section{Doping and the crisis of sport}

The issue to be discussed here is how much impact doping makes upon sport. A good example is Reiterer's (2000) confessions in his book entitled "Positive". This book was published immediately before the Sydney Olympic Games, which the president of the International Olympic Committee referred to as "the best Olympic Games ever" (Samaranch, 2000). Reiterer (2000) achieved excellent results at the Seoul Olympic Games and the Barcelona Olympic Games as well as at the Commonwealth Games three times. He was a natural athlete who did not use drugs to enhance his performance. The book reveals how he eventually tried his hand at drugs and became a normal athlete in the competitive sports circle. Reiterer (2000) says the following:

I have never known clean sport. By the time I was born, in 1968, the Olympics was well into its second decade of widespread doping. In Mexico City that year, many of the top-ranking athletes on display had used, or were using, some type of performance-enhancing drug. Few had any choice. (p. 1)

Drugs, which were made possible by the progress of scientific technology, surround our daily lives and have created a climate that allows doping to spread. The widespread doping in modern competitive sport may be inevitable.

Doping in modern competitive sport presents extremely important issues to discuss in terms of the significance of sport and the way that human beings are supposed to be. The question of whether doping should be approved goes beyond that of ethics and health. It should lead to the questions of what sport is, what natural human beings are like, and what natural human bodies are (Hata, 2003, p.127).

Bette and Schimank's (1995) study clearly reveals how intricate factors come together to make up the doping issues. Sport is structurally undermined by doping, putting their existence at risk. Does that, however, mean the existence of human being in sport is also at risk?

It is surely a question of the existence of human being if drug-use endangers athletes' health. Given that doping is conducted in secret, then athletes cannot make public the side effects, which they suffer from as a result of drug-use. When this happens, athletes are mentally and physically at the risk through doping. Kimura (2003) gives her perspective concerning this situation and says a view shared by German philosopher, Lenk and Pilz (1989). "Being an athlete is becoming one of the most risky occupation, without the public knowing it" (Kimura, 2003, p.118). We believe that we should not give up efforts to expose all drug-use-cover-ups, even though it is practically impossible.

Gardner (1989) argued that the use of performance-enhancing substances is against for the nature of an athlete qua human. The thing that is philosophically important to the doping issue is not to approve guidelines as to which drug should be prohibited and which one not. Nor is it a technical issue of how to prevent the unfair act of doping. It is what negative impact doping has upon sport and human being and how we can find a means to overcome it through philosophical contemplation. As for the philosophical contemplation, Hyland's (1990) argument has concern with our discussion. He brings the idea of what human nature is into question when discussing the ethics of doping (Hyland, 1990, pp.47-69). The concept of the human nature that we consider does not merely mean biological nature. It also means essential nature. Brawn (2001b) says the following: 
Perhaps we are tempted to require in athletes only what is natural. But our sports have evolved with our technology and our best athletes are often unnaturally, statistically, endowed with abilities and other characteristics far beyond the norm. (pp.139-140)

What needs to be emphasized at this juncture is that the crisis of modern sport, symbolized in doping, is really a crisis of human being. It is necessary to look more carefully into the human nature to examine an origin of its crisis. It is mind-body and experience problem that should be discussed in relation to this issue.

\section{Danger of modern sport and an idea of a person's body}

Brawn (1980) considered the doping problem as an issue of fairness. According to his argument, it is possible to be lifting ban of doping, however, it cannot solve the broader doping problems that have been discussed.

Lavin (1987) argued for basis to regulate drugs. What has been discussed in his argument is that the consensus is important in regulation over the use of drugs. Simon (1991) supports this argument with respect to the consensus in the interest groups. He writes, "Unless it can be shown that such decisions are arbitrary, dogmatic, or authoritarian, the fact that they are promulgated by legitimate governing bodies of sport gives them significant moral weight" (Simon, 1991, p.89). They share certain similarities in that both treat the prohibition of doping from a technical viewpoint. We believe it is not of great importance to set up conditions to prohibit drugs from a technical point of view. We will give philosophical consideration to the origin of this crisis in modern sport, which is, more concretely, a consideration of a person's body, our following discussion.

Conventional sport ethics focuses on the question of athletes' physical health, especially the side effects of drug-use. It is based on the idea that doping should be prohibited because it does harm to athletes' health.

Inagaki (2003), who attributed the doping issue to the theories governing the modern era, presented a completely different idea of a person's body. "The main theme for the philosophical consideration of the doping issue involves the principles of competition and the issue of independence in modern society" (Inagaki, 2003, p.125). He claims that the issue of doping, as well as that of organ transplants and of cloning, is one that requires a redefinition of the notion of human existence. Central to this theme is the issue of independence.

Descartes (1637/1986) is the father of well-known theory of the dualism in mind and body (pp.27-28) which seems to dominate the modern world. The development of science and the establishment of the independence of human being have made a worldview based on dualism widespread and which has characterized the modern era. The development of science in the modern era naturally influences sport science. The issue of the influence of sport science clearly presents itself in the separation of a person's body from the existence of the person for the purpose of scientific studies. If Descartes (1637/1986) was the founder of the modern era and we live in the shadow of his theory, the fact that a person's body is both a subject for scientific study as well as being the vessel for our existence is not a mere coincidence. That is because Descartes' (1637/1986) way of thinking treats nature only as material rather than as having life. That is not a nature that gives life to those around it, but a nature that is defined by reason and human control. Those with this view of nature think that they can also control a human body.

People use the phrases such as, harmful to a body and good for your body, in discussing doping. These phrases exemplify the influence of this view of nature that objectifies a human body. An example of this view can be seen in modern Japan as well. Widespread body decorations and cosmetic surgery demonstrate that people see their bodies as mere objects. They decorate their bodies and enjoy seeing them as if their bodies were others' bodies.

Those who practice doping share this view of objectifying their own body. They try to win by altering their body through doping. Not only organizers and officials of competitions, but athletes themselves, objectify their bodies as being a different entity from their whole self. One of our missions is to give critical consideration to this thought and to discuss ways to solve these crises facing modern sport. 


\section{The idea of a person's body in relation to overcoming the crises facing modern sport}

The most important thing to do is to secure independence for athletes. We want to consider the issue of a person's body within the framework of existence and possession. Fromm (1976) discusses the question of existence and possession under the title of "To have or to be?". He explains that to have and to be are the basic principles of how human beings are (Fromm, 1976, pp.22-24). To have is a normal activity in our lives. As a matter of fact, we have a house, clothes, and food to live, not to mention our bodies. To treat a body as a possession such as a house or clothes comes from the aforementioned modern view of nature (Fromm, 1976, pp.85-86). Then, what is to be? Fromm (1976) says as follows. "Having refers to things and things are fixed and describable. Being refers to experience, and human experience is in principle not describable" (Fromm, 1976, p.87).

The issues of a person's body concerning doping emerged as a problem of possession (to have) and existence (to be) because of the above consideration. The dimension of existence concerning a person's body is important in this paper. We will propose an idea, which criticises the view of the body as a self-possession, as a means for conquering the crisis of the decreasing social value of modern sport by examining Eastern Zen philosophy. In the field of sport philosophy, Hyland (1990) and Thomas (1983) had made references to sport and Zen philosophy. They considered Zen philosophy as a problem of "peak experience for self-knowledge" (Hyland, 1990, pp.77-84) and "integration of mind and body" (Thomas, 1983, pp.35-37, 120) respectively.

We have discussed many ideas and thoughts so far from an angle in a manner which is different from their work. The concept connecting these thoughts to sport philosophy is that of achievement. Our proposal, a definition of achievement based on Zen philosophy, is different to the definition of achievement upon which modern sport bases its existence, which gravitates around quantification and the principles of competition (Hata \& Sekine, 2000). "We should create a new sports culture, one that is different to the modern sports culture in its quality"
(Kimura, 2003, p.119). It is surely unrealistic, though, to propose a new system completely different from modern sport (e.g., doing pure recreational activities at Olympic Games, instead of competitions). We want to focus on Kimura's (2003) point, "difference in its quality" (p.119), and try to consider ideas to overcome the crises facing modern sport.

Before talking about Zen in more detail, we want to provide some outlines of its main ideas. Zen emphasizes experiences more than words. Compared to science, it uses experiences to grasp truth, while science gains awareness through knowledge and logic from data (Suzuki, 1938, pp.3-196). One needs "egolessness" (Suzuki, 1938, p.98) in trying to grasp truth, a concept to be referred to later in this paper.

The content of the argument of achievement and Zen philosophy can be seen in the words of Lenk $(1983,1990)$. He has developed his sport philosophy around the concept of achievement. He refers to Herrigel's (1951) and Suzuki's (1938) thoughts:

Zen in sport is high fashion; yoga techniques are incorporated in mental training. The Tao and the art of inaction, of the flowing, adaptive refusal to be frustrated, are recommended to sportsmen and women as well. Zen culture in particular found its way into fashionable training courses which deviated from traditional patterns of teaching, after Eugen Herrigel's pioneer work Zen in der Kunst des Bogenschiessens (Zen and the Art of Archery). In this process Suzuki's reference to Zen teaching in the old Japanese art of swordfighting played a special part. The basic idea is: 'Technical practice by itself is not enough' as Suzuki repeatedly emphasizes (Lenk, 1990, p.37).

What is needed to reach a point you cannot reach solely through technical practice? Zen teaches that competing is not enough. Indeed, one needs to compete to improve a record or simply to stand out from the crowd. We perceive this level as the stage of to have. It upholds the system that has spawned doping and commercialism in sport. Trying to stand out through competition is the backbone of Western culture. Zen's emphasis on experiences and its training method are designed for to be, not to have. 
They orient themselves in a different direction from achievement through competition.

The significance of the training for to be goes beyond how much you have improved your skills in technical practice. That is a humanistic significance. Practice sessions have positive significance in Japanese culture, as described by Herrigel (1951) in his experience of the Japanese art of archery. The significance is that complete devotion to practice brings about changes in the person's inner self (Inoue, 1999).

Zen's training for to be allows you to have experiences of bliss, which are beyond mere excellence in skills or self-interest. Lenk (1990) explains it as follows:

Can sporting activity such as Japanese swordfighting or the art of archery communicate intensive experiences which give these activities the joy of the extraordinary? "Beyond boredom and fear", as Csikszentmihailyi entitled his bookand also beyond preoccupation and outward reward? For their adepts, all such activities that are ends in themselves are their own reward. In this way sporting activity, self-motivated and free from external goals can find its deeper meaning in the process and the experience, in full commitment (p. 43)

Zen argues that pleasure from an activity is not momentary but eternal. Suzuki (1938) calls the mental state accompanied by the activity "egolessness" (p. 98). He explains that egolessness does not mean no-thought, no-idea, or no-emotion, and says as follows:

It means to let your natural faculties act in a consciousness free from thoughts, reflections, or affections of any kind. This state of mind is also known as egolessness (muga) in which you cherish no egoistic thoughts, no consciousness of your own attainments (Suzuki, 1938, pp.97-98).

Although it is said that both tendencies, to be and to have, are present in human beings (Fromm, 1976, p.105), modern technologies "will continue to change our lives and our conceptions" (Brown, 2001a, p.163).
True pleasure from human action is not a matter of to have, such as fame or profit. To have may bring you temporary gain, but never an eternal one. "The truth is that both the having and the being modes of existence are potentialities of human nature" (Fromm, 1976, p.100). Here, we must consider what human being entails, especially in regard to our states of mind. We may then discover the ideal state of achievement, stillness and completion, both in sport and in life.

\section{Conclusion}

For athletes, to be, not to have, is of greater importance, whether in terms of competitive results or health. If athletes as well as others concerned stay at their level of to have, in terms of the thoughts of their body or of monetary rewards, the sports world cannot break out of its current vicious circle.

To be in this study is directed to what Zen calls experiences and what Lenk $(1983,1990)$ calls achievement based on individual actions. To be attitudes can be realized through social support of a better quality of sport, and it will eventually save sport from the current crises.

Why the crisis of modern sport should be conquered? We are able to answer for this question through citing Brown's (2001a) words, "it is worth noting that there are few other experiences in life outside of sports where we feel so unified in mind and body, where the distinction between being persons and having bodies seems so fatuous" (p.160).

Here is our answer to Kimura's (2003) proposal, "to create a new sports culture, one that is different from modern sport in its quality" (p.119) and the conclusion of this study. It is that we should create a new sports culture, oriented to to be, and become less concerned with to have. This requires our society to provide situations where one can have a direct experience to understand to be. Society also has to give opportunities for self-achievement experiences. To sum up, the major characteristics of self-achievement experiences, stillness and completion are of significance. Stillness is an attitude that we showed by examining relationship Zen philosophy and achievement. Completion means experience concerning human existence. 
Athletes need to be less concerned with to have a part of the body temporally for a victory. In other words, they should stop objectifying their body through doping. To be is more crucial for athletes. They have to look at and assess their body, taking their life after their athletic careers into consideration. What counts is not gaining something through their body, but living in harmony with it.

These are the principles we propose to save the sports world from its current crises. We sincerely hope that educational programs will be made for athletes and officials based on these principles. We also believe that these principles will help to create a new sports culture and to remove public distrust of the current sports world. In concluding, we should note that there is a way to conquer the crisis of modern sport by articulating the dimension of self-achievement experiences as the principle for athlete's performance.

\section{Acknowledgments}

The authors would like to acknowledge the financial support of the Japan Society for the Promotion of Science who awarded the Grant-in-Aid for Scientific Research (C) (1), No.15500416, 2003-2006 that made this study possible. Our thanks are also due to the reviewers for helpful suggestions and comments.

\section{References}

Bette, K.-H., \& Schimank, U. (1995). Doping im Hochleistungssport [Doping in athletics]. Frankfurt am Main: Suhrkamp.

Brawn, W. M. (1980). Ethics, drugs, and sport. Journal of the Philosophy of Sport, 7, 15-23.

Brawn, W. M. (2001a). As American as Gatorade and apple pie: Performance drugs and sports. In W. J. Morgan, K. V. Meier, \& A. J. Schneider (Eds.), Ethics in sport (pp.142-168). Champaign, IL: Human Kinetics.

Brawn, W. M. (2001b). Paternalism, drugs, and the nature of sports. In W. J. Morgan, K. V. Meier, \& A. J. Schneider (Eds.), Ethics in sport (pp.130-141). Champaign, IL: Human Kinetics.

Descartes, R. (1986). A discourse on the method of rightly conducting the reason, and seeking truth in the science. In J. Veitch (Trans.), A discourse on method: Meditations and principles (pp.1-62). London: J.M. Dent \& Sons. (Original work published 1637)

Fraleigh, W. P. (1985). Performance-enhancing drugs in sport: The ethical issue. Journal of the Philosophy of Sport, 11, 23-29.

Fromm, E. (1976). To have or to be?. In R.N. Anshen (Ed.), World perspectives (Vol. 50). New York: Harper \& Row.

Gardner, R. (1989). On performance-enhancing substances and the unfair advantage argument. Journal of the Philosophy of Sport, 16, 59-73.
Hata, T. (2003). Dôpingu mondai o tetsugaku suru [Consider doping problems philosophically]. Taiiku Genri Kenkyû [Journal of the Philosophy and Principles of Physical Education], 33, 115-116, 127-128. (in Japanese)

Hata, T., \& Sekine, M. (2000). The meaning of sport: An essay in philosophical anthropology. In International Association for the Philosophy of Sport (Ed.), Sport and the body: Programme and abstracts (pp.11-12). Melbourne: Victoria University.

Hyland, D. A. (1990). Philosophy of sport. New York: Paragon.

Herrigel, E. (1951). Zen in der Kunst des Bogenschiessens [Zen in the art of Japanese archery]. Bern: Otto Wilhelm Barth Verlag.

Inagaki, M. (2003). Dôpingu mondai o tetsugaku suru: Supôtsushi kenkyû no shiten kara [Consider doping problems philosophically: From the viewpoint of sport history]. Taiiku Genri Kenkyû [Journal of the Philosophy and Principles of Physical Education], 33, 122-127, 131-132. (in Japanese)

Inoue, S. (2000). Shintai undô ni okeru kansei towa nani ka. [What is the sensibility for human movement?]. Journal of the Philosophy of Sport and Physical Education, 22 (1), 32-33. (in Japanese)

International Olympic Committee. (2003). Olympic charter (In force as from 4 July 2003). Lausanne, Switzerland: Author.

Kimura, M. (2003). Dôpingu mondai o tetsugaku suru: Supôtsushisô kenkyu no shiten kara [Consider doping problems philosophically: From the viewpoint of thinking on sport]. Taiiku Genri Kenkyû [Journal of the Philosophy and Principles of Physical Education], 33, 116-120, 128-129. (in Japanese)

Lavin, M. (1987). Sports and drugs: Are the current bans justified?. Journal of the Philosophy of Sport, 14, 34-43.

Lenk, H. (1983). Eigenleistung: Plädoyer für eine positive Leistungskultur [Self-achievement: Argument for a positive performance culture]. Zürich: Edition Interfrom.

Lenk, H. (1990). Zen, the experience of 'flow' and the meditative dimension in sport. In M. Eda (Ed.), Tsukuba international workshop on sport education (pp.37-44), Tsukuba, Japan: University of Tsukuba.

Lenk, H., \& Pilz, G.-A. (1989). Das Prinzip Fairness [The plinciple of fairness]. Zürich: Edition Interfrom.

Morgan, L. (2003). Enhancing performance in sports: What is morally permissible?. In J. Boxill (Ed.), Sports ethics (pp.182-188). Oxford: Blackwell Publishing.

Reiterer, W. (2000). Positive: An Australian Olympian reveals the inside story of drugs and sport. Sydney: Macmillan.

Samaranch, J.A. (2000). The best Olympic Games ever. Olympic Review [On-line], October-November 2000. Available: http:// www.olympic.org/uk/news/olympic_news/review_uk.asp?

Schneider, A. J., \& Butcher, R. B. (2000). A philosophical overview of the arguments on banning doping in sport. In T. Tännsjö, \& C. M. Tamburrini (Eds.). Values in sport (pp.185-199), London: E \& FN Spon.

Simon, R. L. (1991). Fair play: Sports, values, and society. Boulder, CO: Westview Press.

Suzuki, D.T. (1938). Zen buddhism and its influence on Japanese culture. Kyoto: The Eastern Buddhist Society.

Tamburrini, C. M. (2000). What's wrong with doping? In T. Tännsjö, \& C. M. Tamburrini (Eds.). Values in sport (pp.200-216), London: E \& FN Spon.

Thomas, C. E. (1983). Sport in a philosophic context. Philadelphia: Lea \& Febiger. 


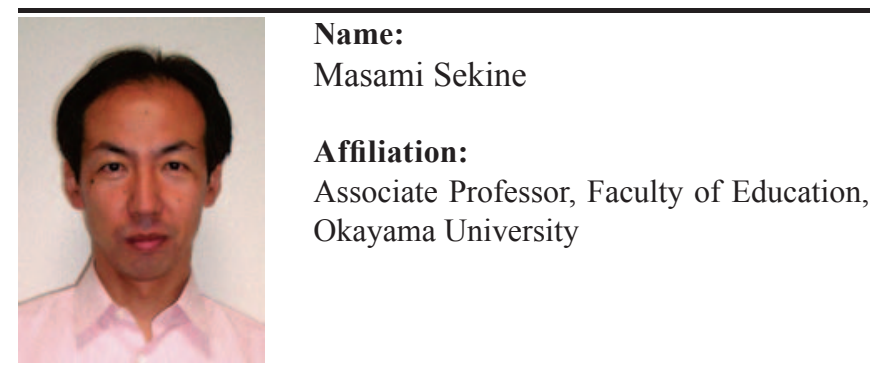

\section{Address:}

3-1-1 Tsushimanaka, Okayama 700-8530, Japan

Brief Biographical History:

1989-1996 Doctoral Program in Health and Sport Science, University of Tsukuba

$1996 \mathrm{PhD}$, University of Tsukuba

1996-1998 Assistant Professor, Okayama University

1998- Associate Professor, Okayama University

\section{Main Works:}

- A Philosophical Study of Sport: An Achievement Thought of Hans Lenk. Fumaidô Shuppan, Tokyo, 1999.

Membership in Learned Societies:

- Japan Society of Physical Education, Health and Sport Sciences

- Japan Society for the Philosophy of Sport and Physical Education

- International Association for the Philosophy of Sport 